\title{
“Before Occupy Central, I Wasn't Concerned”: Examining Participatory Visual Research for Social Change with Hong Kong-based Filipina Youth
}

\author{
CASEY BURKHOLDER \\ McGill University
}

\begin{abstract}
This article describes a participatory visual research project with two Hong Kong-based Filipina young women, and explores their understandings of citizenship and civic engagement through cellphilm-making (cellphone + filmmaking), collaborating on the writing of an academic article, and co-presenting research findings at an academic conference in Calgary, Canada. The study finds that Hong Kong's Occupy Movement encouraged the participants to see themselves as engaged citizens, participate politically in the territory, and work toward social change for ethnic minorities by engaging different audiences through multiliteracy practices in a research for social change framework.
\end{abstract}

\section{Keywords}

ethnic minorities, Hong Kong, participatory visual research, social change, youth

\section{Introduction}

Writing in 2007, Blackburn and Clark suggest that "the need for literacy research that advocates for social justice, fosters political action, and produces real change in the lives of oppressed and marginalized people has never been more urgent or more real" ( $p$. 1). In 2017, the need for literacy research that engages participants and communities to enact real change remains paramount. As a teacher and researcher, I have been interested in working with students and participants to examine their lived realities and to collaborate on ways to address community challenges and social inequalities through project based learning and a research for social change framework. As Mitchell and Burkholder (2015, pp. 649-650) argue, in a research for social change framework:

the goal is for researchers to work with communities to advance what might be termed as knowledge 'from the ground up' (Choudry \& Kapoor, 2010) ... Exploring how communities see the world, what they consider to be critical issues and how policy dialogue can be galvanized through public discussion and critical consciousness are issues that are fundamental to a research for social change framework.

I began my teaching career at a public secondary school in Hong Kong. I approached my first classroom with my privileged white Canadian gendered Englishspeaking lens, and at the time, I had prescribed ideas about how multiculturalism should look within the context of school - drawing heavily on the 'cultural mosaic' discourses that were the norm in my teacher education preparation. My students were multilingual and multiethnic young people who were taught with English as the Medium of Instruction, and who were described in policy discourses "non-Chinese speaking" but more often than not referred to as "non-Chinese" (Burkholder, 2013). While teaching at the school, I was 
horrified by the ways these ethnic and linguistic minority students were segregated from the Chinese-speaking students in courses, in extra-curricular activities and in physical spaces in the school (including, for example, a separate lunch room). Ethnic minorities make up 6\% of Hong Kong's population (HKSAR, 2011), and issues relating to how they should be included or integrated into schools continue to play out in the media, government policy discourses, directly affecting the lives of marginalized young people. When I was a teacher, I tried to work within the school to make changes for these marginalized students. I ate with the students every day, bringing vegetarian extras for those who did not have lunch. After school, I played hours of badminton and basketball with the kids who were not anxious to go home at the end of the day. In our 'NC' or 'non-Chinese' student staff meetings, a few colleagues and I would advocate for more inclusion for our learners within the school. However, I left the school after two years, and realized that my efforts were very small scale. Overall, the unequal situation had not changed much for my students. I kept in touch with my class, and later came back to Hong Kong in 2013 to undertake my Master's research with my former students. The study presented a qualitative ethnographic exploration into these learners' lived experiences of school and contrasted these experiences with government discourses of 'inclusion' and 'support' (Burkholder, 2013). I found that these ethnic minority young people felt disconnected from the larger Hong Kong society, and their multilingual and multiethnic realities were presented by the government and their schools through a deficit lens. However, the results of this research were published in my thesis and in an academic article, and did not reach the communities within which I worked, nor did it make any change at a local or policy level. I began to think about the audiences for these academic texts, and wondered how I might convey research findings to my participants, their communities, and the larger Hong Kong society.

Following these findings, and my feeling of continued frustration, in 2015 I came back to Hong Kong work with my former students on my doctoral research project that examines ethnic minority young peoples' sense of self, belonging, and civic engagement in their young adult lives. For my doctoral study, I wanted to subscribe to a research for social change framework, and thus decided to engage in participatory visual research with participants so that the products and results of the research might more easily reach the communities within which we were working. This article takes up a piece of this research by focusing on a collaboration with two Filipina young women in the wake of Hong Kong's 2014 Occupy $^{1}$ movement. Taking up issues of civic engagement, identity, and belonging at this particular time in Hong Kong through a research for social change framework has raised some provocative questions. In this study, I ask: How do Filipina young women

${ }^{1}$ From September - December 2014, a large number of Hong Kong citizens protested an increasing Mainland Chinese political presence in the territory by occupying specific commercial and economic districts (including Central, Admiralty, Causeway Bay and Mong Kok). The protesters' peaceful occupations were met by police actions (including the use of tear gas) which protestors tried to block with the use of their umbrellas, resulting in the "umbrella revolution." The Umbrella Revolution was seen as a youth-led act of civic engagement that worked to articulate Hong Kong's distinct political, linguistic, and social identity (Jones \& Li, 2016). Although the occupations ended in 2014 , the movement continues to have an effect on the territory's social and political landscape. 
explore notions of civic engagement in post-Occupy Hong Kong through cellphilmmaking, collaborative writing, and co-presenting as multimodal literacy practices? How might Filipina girls' media-making practices be disseminated meaningfully across communities, spaces, and geographies through a framework of research for social change? These are central questions that frame this article.

\section{Locating Research for Social Change as a Literacy Practice}

Research for social change, including for example action-based and participatory visual research projects, provide a specific way of looking at individual and community challenges, as well as subscribing to methods and working with people to address these challenges and opportunities. Locating this study in a research as social change framework, I look to the work of Schratz and Walker $(1995$, p. 1) to remind us that for some researchers and practitioners, research for social change requires examining everyday experiences with participants in order to make change, and "...finding ways to seize the opportunity to become more reflexive in their practice, that is to say creating the means for looking at the situations in which they act as others in the situation see them."

How might research for social change be conceptualized as a literacy practice? In as early as 1994, Julian Sefton-Green and David Buckingham wrote on the importance of acknowledging the situated nature of people's local literacy practices, and examining the ways that citizens might collaborate and inquire together to take action and make a difference in their communities and societies. The New London Group's (1996) suggestion that a reframing and opening up of traditional autonomous understandings 'literacy' work to situate research for social action theoretically as a multiliteracy practice. Multiliteracies have been described by scholars such as Cope \& Kalantzis (2000, p. 5) as focusing:

on modes of representation much broader than language alone. These differ according to culture and context, and have specific cognitive, cultural and social effects...[where] language and other modes of meaning are dynamic representational resources, constantly being remade by their users as they work to achieve their various cultural purposes.

Other scholars working within a multiliteracies framework (see for example, Barton \& Hamilton, 1998; 2001; Dyer \& Choksi, 2001; Gee, 1996; 2001; Purcell-Gates, 2007; Rowsell \& Pahl, 2015) explore the ways in which literacy practices might be employed in research and activist projects with an aim toward social change. Importantly, Goodman (2003, p. 4) contends that:

historically, the way in which poor and other marginalized groups have managed to become visible, to demand political recognition and economic rights, has been through the acquisition of literacy in the dominant medium. However, the dominant medium is changing. Learning to read and write the printed word is still essential, but is no longer sufficient in a world where television, radio, movies, videos, magazines, and the World Wide Web have all become powerful and pervasive sites for public education and literacy. 
Street (2014) agrees and argues that new literacies are also politically, culturally, and socially situated. New literacies include more than just the acquisition of technical skills (such as reading or writing or filmmaking). To this end, by examining the power of new literacies for social change through the case studies of entertainment programming, Singhal and Rogers (2012, p. 9) argue that these programs can affect individuals' behaviour (they provide the example of radio soap operas encouraging people to use condoms) as well as communities' practices.

This article examines the ways in which literacy practices can be taken up within a research for social change framework by looking at three specific literacy practices: cellphilming (cellphone + filmmaking, see MacEntee, Burkholder \& Schwab-Cartas, 2016), collaborative writing for publication, and co-presenting research findings with participants at an academic conference. These examples of literacy practices act as opportunities to disseminate research findings with participants, and I argue that each of these practices are specific acts of civic engagement, supported within a research for social change framework.

\section{Exploring Youth Civic Engagement}

What might an understanding of civic engagement mean in relation to the civic actions of youth actors in Hong Kong? Ku and Pun (2011) describe the way that citizen productions of civic engagement in Hong Kong is most acceptable if it honours the territory's commitments to global capitalism and 'one country, two systems' China. $\mathrm{Ku}$ and Pun caution that this binary creates a "specific ethic of self and citizenry - an apolitical and yet productive economic subject - to live up to the project" (p. 1) of Hong Kong as both a global city and a distinctly Chinese territory. In a discussion of Hong Kong citizenship, Kennedy, Hahn, and Lee (2008) argue that "on the surface, it is tempting to think that Hong Kong citizens reflect thin conceptions of citizenship" (p. 59) as democracy is limited, and civic engagement might be limited to acceptable social practices (rather than dissent) and prescribed economic participation. In light of the Occupy Movement, I suggest that conceptions of citizenship in Hong Kong must be understood as more than just passive. Rebellious forms of civic engagement - those which are exemplified in the Occupy Movements in Hong Kong and elsewhere - are seen as dissenting and disruptive forms of civic engagement as these youth actions interrupt commercial and economic interests, disrupting business as usual. These dissenting forms of civic engagement are most useful in framing this study as research for social change. To this end, the study aligns with Jenkins' (2016, p. 29) conception of "civic imagination," which encourages actors to imagine a better political, economic and social future for themselves and their communities. This civic imagining requires citizens to see themselves (and to act accordingly) as "active political agents."

Buckingham (2000, p. 205) argues that young people are often presented as a homogenous group of political actors, and their political actions and literacy practices (e.g. tagging public spaces, withdrawing, speaking out) are "frequently framed as a problem, whether implicitly or explicitly." These political actions are perceived by adult power structures (e.g. governments and the police) in relation to adults, and young people's specific forms of political expressions are sometimes put forth as problematic (unless these expressions align with adult expectations). In her work on girls' productions of citizenship, Harris (2005) offers a gendered perspective that aligns with Buckingham's work. She 
suggests that girls' citizenship practices are often taken up by the dominant society as "the focus for both concerns about social unbindings and the learning of good citizenship, which is based on individual responsibility" (p. 67). Traditionally acceptable productions of civic engagement can include acting as a 'good citizen' such as abiding laws, but Buckingham, Harris and others (see for example, Roholt, Hildreth \& Baizerman, 2014) include shifts toward activism in their writing on youth civic engagement.

Much work on citizenship has been taken up through colonial and masculine discourses, which may alienate girls, women, and gender non-conforming individuals' specific citizenship practices (Arnot \& Dillabough, 2000). Since nationhood, territoriality, colonialism and liberal democracy all factor greatly into many interpretations of citizenship and citizenship practices (see for example, Marshall, 1977; Packham, 2008; Turner, 1990), I have faced a critical juncture in my engagement with the body of work as it relates to young people's productions of civic engagement. I argue that it is paramount that the ways in which young people in Hong Kong practice citizenship outside of a democratic framework must be explored in detail. In examining a cellphilm making project with girls, as well as a discussion of collaborative writing and co-presenting, Filipina girls' media productions of civic engagement (as critical multiliteracy practices) are taken up in this study.

\section{Participatory Visual Research}

\section{Methodology}

Participatory visual research projects frequently operate within a research for social change framework, and highlight the economic, social and political contexts where participants live, work, and study. Participatory visual methodologies, including such methods as drawing (Theron, Mitchell, Smith, \& Stuart, 2011), photography (Ewald, Hyde \& Lord, 2012), photovoice (Wang \& Burris, 1997; Wang, 1999), digital storytelling (Gubrium \& Harper, 2013), participatory video (Milne, Mitchell \& de Lange, 2012), and cellphilms (Dockney \& Tomaselli, 2009; MacEntee, Burkholder \& Schwab-Cartas, 2016; Mitchell \& De Lange, 2013) expose participant and community realities through visual representations. Participatory visual methodologies often promote researching with individuals and communities, rather than research on or about these actors. As Mitchell \& Burkholder (2015, p. 657) discuss, participatory visual methods inspire research participants to "document their own notions of community building, literacy, citizenship and critical consciousness and what social justice looks like to them. In turn, this approach is expected to generate policy dialogue about the existing and desired educational, literacy or health rights of participants through their voices and through their viewpoints." In examining photography projects with teachers and young people as opportunities to engage in research for social justice, Ewald et al (2012) suggest that these methods might be used as ways to move from theories of social justice to inspiring others within the community (including policy makers) to understand citizens and communities' concerns and move toward individual, community, and policy change. In the context of HIV/AIDS health education research in South Africa, Michell, Stuart, De Lange, Moletsane et al. (2010) explore the ways in which participatory visual methodologies might be used to shift individual participants' behaviors and encourage important community conversations, specifically about the role of gender-based violence and its implications for HIV/AIDS in the context of South Africa. Importantly, participants' visual productions must be 
understood in relation to visual cultures and cannot be divorced from their social, political, economic or spatial contexts (Rose, 2014). To this end, Stuart and Mitchell (2013) argue that using visual methodologies is helpful in working with children and as they are adept of representing their ways of knowing and experiencing and sharing these with adults and decision makers to address their needs and challenges within their homes, schools, and communities.

Working within a participatory visual methodologies as research for social action framework, this study considers cellphilming as its method, and explores the ways in which Filipina girls act as co-researchers, by creating short cellphilms, collaborating on the writing of an academic article, and co-presenting research findings at an academic conference in Canada.

\section{Cellphilming}

Jonathan Dockney and Keyan Tomaselli (2009) developed the term 'cellphilm' to address the practice of filmmaking with mobile technologies (cellphone + filming). Claudia Mitchell, Naydene de Lange and Relebohile Moletsane's research-with teachers in KwaZulu Natal, South Africa to address gender-based violence as well as individual and community concerns in the context of HIV/AIDS - have advanced cellphilming as a participatory visual methodology. Cellphilming-as a method-builds from the pervasiveness of cellphones, as well as from citizens' everyday media-making practices. As MacEntee, Burkholder \& Schwab-Cartas (2016, p. 8) argue:

Incorporating cellphones, given their accessibility, in research practice across different contexts could be seen as a way of taking advantage of local technology. This idea can be framed by Dyson's (2015) concept of domestication and the particular ways in which cultural groups not only make a technology their own by adapting it to their needs and agendas, but also adapt their behaviours to the technology. As Baron notes, the practices surrounding mobile phones are determined partly by the devices themselves and partly by the "cultural norms - or pragmatic necessities - of the society in which they are embedded" (2008, p. 131).

In my own practice, as a teacher in Hong Kong, I noticed the everyday ways that my students used their cellphones to film moments from their days: from making up dances to recording moments at lunch time to recording episodes of violence and bullying. I wondered how I might capitalize on these practices within a research space; to reframe what my former students (and now participants) were already doing with their phones and turn these practices toward a particular concern or challenge, in my case, exploring identity, belonging and civic engagement.

Researchers who take up cellphilming as a research method often-but not always - work with participants' and communities' own mobile technologies, potentially contributing to participants' sense of ownership over the knowledge produced (MacEntee, Burkholder \& Schwab-Cartas, 2016). This is a departure from many participatory video projects, where the filmmaking technology is often owned by the researcher, and removed at the end of a project, which may further the power differentials between researcher and the communities in which they work (Schwab-Cartas, 2012; Walsh, 2014). Mitchell, De Lange and Moletsane (2014) suggest that participatory video projects with cellphones as 
the main tool might be empowering as the participants are often familiar with the methods of filming and this familiarity has the potential to democratize the research space. Working with participant and community-owned mobile technologies might also encourage project sustainability, as when the project ends, the participants may continue to explore, film, and share their ways of knowing beyond the scope of the research project.

The ways in which these cellphilms can be shared points to their potential as tools within research for social action. Cellphilms might be viewed on a phone, uploaded to a computer, screened on a projector, or shared across social media. Each of these spaces holds potential for reaching specific audiences - and many with an eye toward social change. The digital realm - and social media sites in particular - are worth examining more closely in a research for social change framework. Jenkins (2016) argues that digital spaces, such as Twitter and Facebook, provide citizens with tools to work toward social change, similar to the role that telephones played in the 1960s Civil Rights movement in the United States. The civil rights movement could not be "reduce[d]" to the "effects of long-distance phone calls," but they played an important tool for "coordinating activities among other black church leaders, freedom riders, and a range of other dispersed set of supporters" ( $\mathrm{p}$. 23). Our cellphilm-making project employed YouTube as a digital archival space to continue to share the cellphilms across geographies and communities in an effort to disseminate information about Hong Kong's ethnic minority young people and their ways of seeing and experiencing life in Hong Kong (Burkholder, 2016b). I turn now to a description of the larger project that this study is drawn from.

\section{Project Summary: We are HK Too}

The study outlined in this article encompasses a piece of my SSHRC-funded doctoral study, Looking back and looking around: Revisiting and exploring civic engagement through cellphilms with ethnic minority youth in Hong Kong, which took place in Hong Kong from January-June 2015 (Burkholder, 2016a; Burkholder 2016b), and continues through digital collaborations (including the creation of a Facebook page, a Twitter account and the monitoring and archiving of cellphilms on YouTube) across geographical expanses. Working with ten of my former secondary students and one new participant (who I did not teach, but who was friends with another participant and wanted to join the study), my doctoral project explores the ways in which ethnic minority young peoples' memories of their experiences in secondary school affects the ways they see themselves, conceptualize a sense of belonging and engage as young adult citizens in Hong Kong society and politics. The research employs qualitative (semi-structured interviews and focus groups) and participatory visual methods (cellphilming) as the youth participants created and shared cellphilms that explored the following questions: 1) who am I in Hong Kong? 2) How do I belong in Hong Kong? and 3) How do I act as a citizen of Hong Kong? As the project began to wind down in Hong Kong and I prepared to return to Canada the research continued in the digital realm as the we created a participant-managed YouTubebased digital archive of the cellphilms, called We are HK too (Burkholder, 2016b).

This study describes a research collaboration with two Filipina participants, Katrina and $\mathrm{Ann}^{2}$, from the larger research project. I begin by examining Katrina' Cellphilm Project 3, which describes her understanding of civic engagement in post-Occupy Hong

${ }^{2}$ Pseudonyms chosen by the participants. 
Kong. The study then considers two further collaborations between Ann, Katrina and I: first writing an academic article together about Filipina experiences in Hong Kong, and then presenting our research findings at the 2016 Language and Literacy Pre-Conference at the University of Calgary.

\section{Findings}

In his 2010 book, Why Voice Matters, Couldry argues that engaging with citizens' voices through their stories and sharing their ways of knowing can encourage other social actors to connect with and act upon these narratives. What is more, these stories are made more powerful when they are situated in their larger political context. This study engages with youth voices, and situates these voices in the larger Hong Kong socio-political context. I begin by looking to with Ann's voice, as she situates the study in her understanding of the role of language and the political reality for Hong Kong's ethnic minorities. She suggests,

The Hong Kong government's vision is to help ethnic minorities to integrate into the society by learning Cantonese in order to become a "local." But isn't the fact that many ethnic minorities have been here for years, many being born here, studying here, working here, raising families here and holding permanent residents' status already make them a local? The fact that the term "ethnic minority" or even "non-Chinese speaking" are used to refer to them and are put into the disadvantaged category in government policies furthers this separation.

Ann provides a personal account of how the terms 'non-Chinese speaking' and 'ethnic minority' are used politically to isolate particular citizens based on their race and language practices. Ann's reflection helps to situate the larger political context that Katrina explores in her cellphilm. Cellphilms - as visual narratives - provide an avenue for participant voices to be disseminated. I now turn to a discussion of Katrina's cellphilm to understand the ways in which she has represented her sense of civic engagement in post-Occupy Hong Kong.

\section{Cellphilming Youth Civic Engagement as a Multiliteracy Practice for Social Change}

Katrina's cellphilm about her sense of civic engagement, Cellphilm Project 3, can be found on the project's YouTube-based digital archive, We are HK Too (https://www.youtube.com/watch?v=E3HwRPhZAjk). Katrina is a young person who lives, studies and works in Hong Kong. She is also an ethnic minority. In her short cellphone-video (cellphilm), Katrina expresses her sense of civic engagement as a Filipina growing up in Hong Kong. Katrina's cellphilm uses stop motion animation combined with edited video where a corkboard acts as the background and Katrina's hands move animations and pieces of text to communicate her story. Music plays, but there is no narration. Instead, the narrative is communicated through textboxes and images, which are organized to move the story along. 


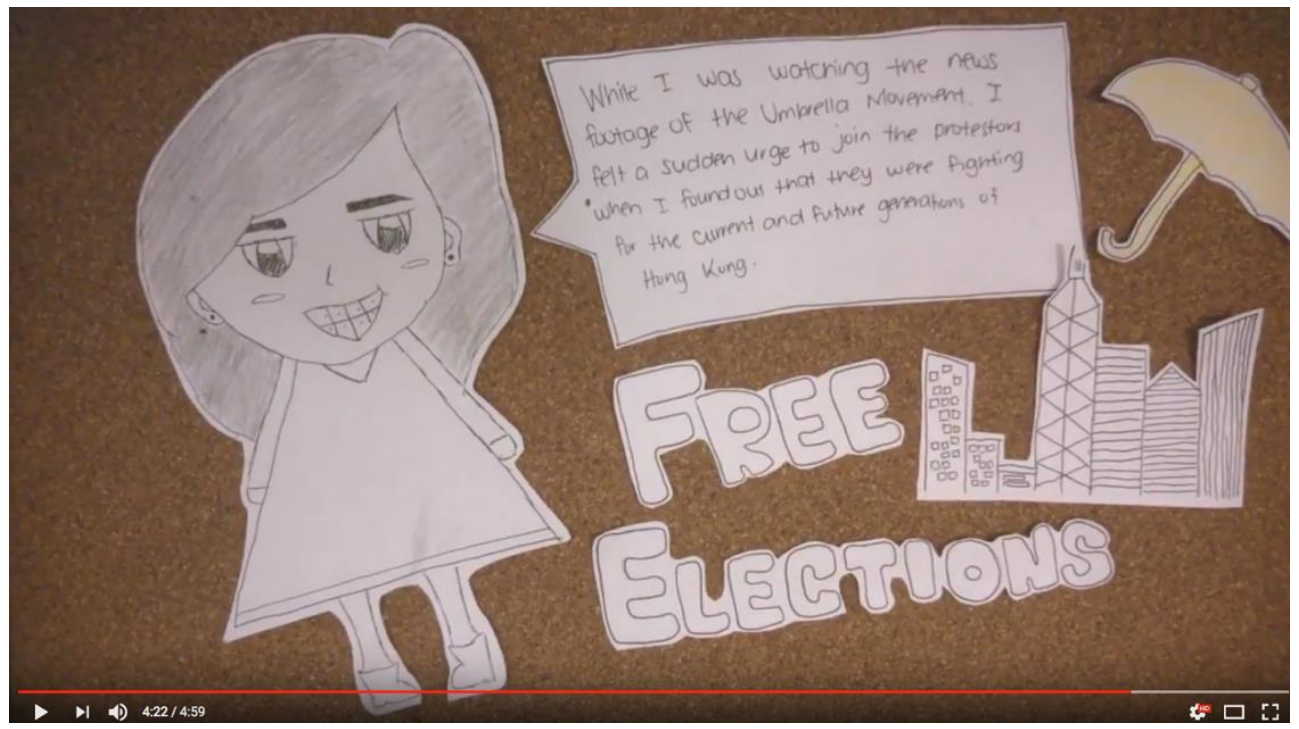

Figure 1. Still from Katrina' Cellphilm Project 3

Katrina begins by introducing the question that inspired the cellphilm, 'How do I act as a citizen in Hong Kong' and moves on to describing her sense of civic engagement. At first, Katrina describes the ways in which she engages as a citizen of Hong Kong in ways that reproduce desirable notions of citizenship. She describes the importance of watching the news, of reading newspapers, of going to the public library. As the cellphilm continues, Katrina begins to grapple with the notion of what it means to be an ethnic minority citizen during the Occupy protests in Hong Kong.

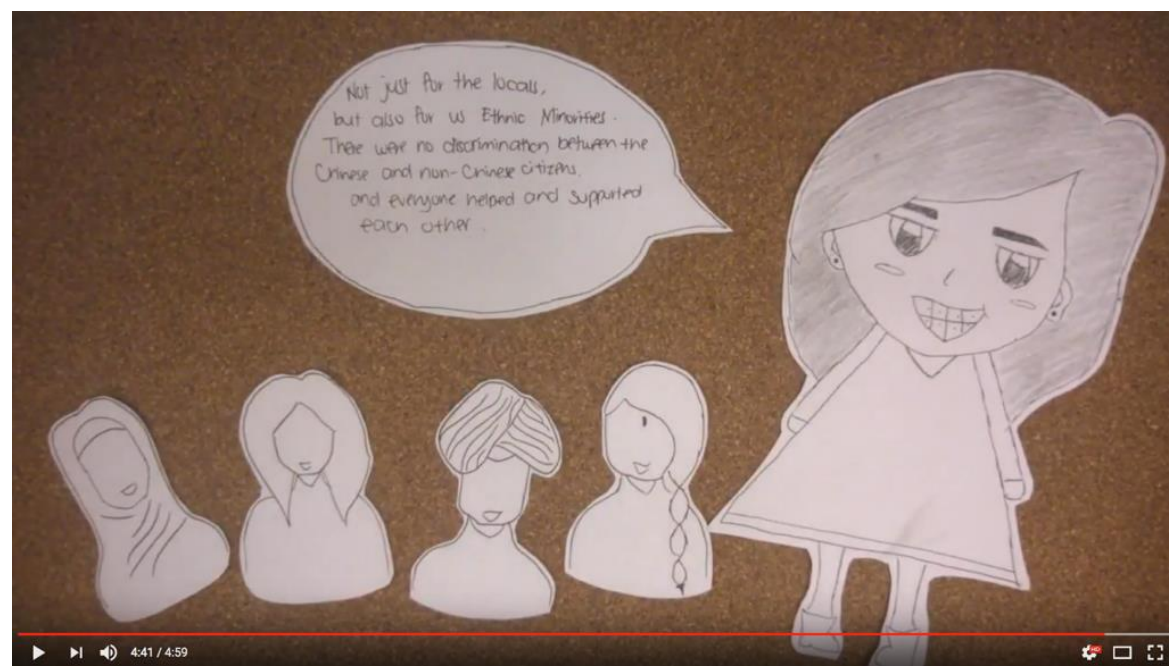

Figure 2. Still from Katrina' Cellphilm Project 3

The Occupy Movement is featured prominently in the cellphilm. Katrina describes the ways that the Occupy Movement encouraged her to become more inquisitive about Hong Kong politics. She begins by describing her understanding of the Occupy Movement, which "reminded me of the rights of Hong Kong citizens for democracy as promised by China in the Hong Kong handover." The Occupy Movement received a lot of local and international media attention, and the conversations brought on by this coverage began to 
influence the ways in which Katrina thought about living in Hong Kong. In the cellphilm, Katrina writes, “before Occupy Central, I wasn't concerned much about what's going around (and to) Hong Kong. But when the tension between the Hong Kong government and pro-democrats started rising, leading to the "Umbrella Movement", that's when I started getting interested and curious on Hong Kong politics." Moving beyond an interest in thinking about the ideas brought on by the protestors, Katrina began to think about how she might engage in activism. She notes, "while I was watching the news footage of the Umbrella Movement, I felt a sudden urge to join the protesters when I found out that they were fighting for the current and future generations of Hong Kong." It is noticeable that Katrina's discussion of the Occupy Movement describes Hong Kong citizens as monocultural, and downplays the social, political, and cultural divisions present in the city between its Chinese-speaking and non-Chinese speaking residents. Katrina notes, "[The Occupy Protests were] not just for the locals but also for us ethnic minorities. There were no discrimination between the Chinese and non-Chinese citizens and everyone helped and supported each other."

These tensions are taken up in her cellphilms on identity and belonging, but are downplayed in the discussion of civic engagement and the desire for increased democratic measures and Hong Kong Independence. Here, cellphilming is a method for social change as it provides an opportunity for Katrina's experiences to be transmitted to audiences through visual means and across digital spaces. Through screenings in Hong Kong (Burkholder, forthcoming), sharing the cellphilm via YouTube, the cellphilm might inspire conversation and impact others' understanding of ethnic minority young people's sense of civic engagement in post-Occupy Hong Kong. While cellphilm method does not necessarily lead to social change, it provides an opportunity for participant narratives to be transmitted across audiences and spaces through their own voices and for their own purposes. In this way, cellphilming, as exemplified in Katrina's Cellphilm Project 3, might be conceptualized as a multiliteracy practice in a research for social change framework.

\section{Collaborative Writing as Multiliteracy Practice for Social Change}

Following the cellphilm-making project, Katrina, Ann and I decided that we wanted to keep our collaboration going, despite our geographical differences. Over celebratory sushi before I left Hong Kong, Ann suggested that we might write an article together where we described our collaboration and how the study (and its methods) made us learn more about ethnic minority experiences in Hong Kong in general, and an exploration of Filipina girlhood in particular. When I arrived back in Canada, I created a Google Doc, and over a period of 5 months, we worked on the creation of an article, which we submitted for consideration to an academic journal. The article considers the nature of Filipina girlhood in Hong Kong, and examines productions of self and belonging through cellphilms. We employ an academic tone in our writing, while simultaneously reflecting on each of our experiences as non-Chinese speaking residents in Hong Kong. As a white, English speaking Canadian woman, for example, in my two and a half years living in Hong Kong, my everyday routines and experiences of the city spatially were never disrupted by police officers. Ann and Katrina, however, noted that they were often stopped by police in their daily lives to check on their legal status in the territory. Our racialised experiences of otherness frame the inquiry, and situate our findings. We began with these personal reflections, and began to shape the article. 
In the writing of the article, each author took on a different font colour in the production of the document. I used green text, while Ann used red and Katrina wrote in blue. At the end of the writing, we had created a rainbow out of our writing. Each author took on a specific role in the writing. Building on my experience in writing for the genre of the academic article, I built the literature review and methodology sections, while Katrina and Ann worked on the findings and discussion sections. We collaborated on the introduction and conclusion, resulting in a piece of writing that is full of each of our voices. As the primary author, I also took on an editorial role to ensure that the article employed traditional academic grammar, but acknowledge that this practice was likely the least participatory part of the co-writing process. The process of writing collaboratively in academic English across time zones and busy school schedules (Katrina, Ann, and I were all enrolled full time in universities during this time) proved to be sometimes slow, sometimes difficult, but ultimately satisfying. The piece has been accepted at a journal, but we are still working together to address revisions. This collaboration has continued beyond the research space, and has more than doubled the time commitment of the initial research project.

In thinking and writing about our cellphilm project, and the experiences of ethnic minorities in Hong Kong, the practice of collaborating on an academic article is a multiliteracy practice in a research for social change framework. Aside from the audiences that are reached through the cellphilm archive and cellphilm screenings (Burkholder, forthcoming), an academic article in a peer reviewed might impact policy makers within Hong Kong and abroad. By collaborating to reach new audiences and work toward sharing Ann and Katrina's experiences in their own voices, the practice of collaborative writing acts as an important continuation of the participatory ethos of the research project. Working together also inspired us to continue our collaborations in a number of ways, including the presentation of our findings at a research conference and the development of a new cellphilm project, this time led by Ann and Katrina, with Casey providing technical and organizational support.

\section{Co-Presenting as a Multiliteracy Practice for Social Change}

As our paper began to take shape, I had the idea that we might present our findings at an academic conference: to encourage the participatory nature of the project from its beginning to the dissemination of the findings. Over a Skype meeting, I proposed the idea to bring Katrina and Ann to Canada to present our findings at the Language and Literacy Researchers of Canada Pre-Conference. Ann and Katrina were excited by the prospect of coming to Canada (it would be their first trip to North America), and we began the long bureaucratic process to attain visas. In our Google Doc, we began to collaborate on an abstract for our presentation, which we titled "This is where I grew up": Reflections on language, civic engagement, and social change for ethnic minorities in Hong Kong. As with the paper, I took on an editorial role while Katrina and Ann articulated the findings sections and I filled in the theoretical framework and methodology. In reflecting on the process, and the idea to come to Canada to co-present, Ann remembers,

When we came up with the idea of going to Canada to present our research paper, it thought it was a crazy idea. But it was that very crazy idea that made this trip happen. My first initial reaction when I finally got my visa is the fact that I'm finally 
going to go out of Asia and present a research on a topic that I am so passionate about and dedicated to.

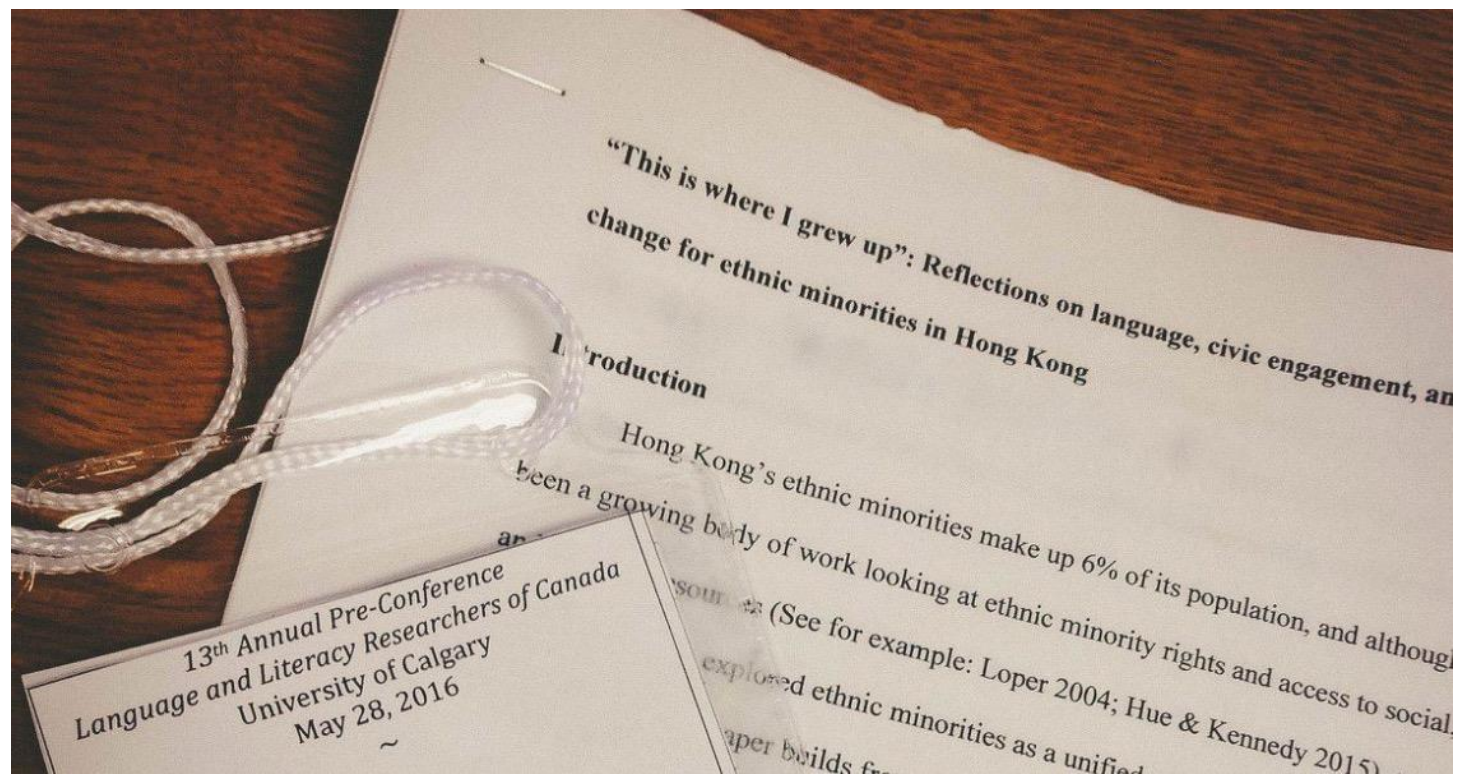

Figure 3. Language and Literacy Researchers of Canada Paper and Credentials

Our paper was accepted, the visas were mailed, and Ann and Katrina prepared to take the trip to Calgary. We began planning our presentation and collaborating again through Google Slides. I took on the introduction, and Ann and Katrina would detail our findings and share some of our cellphilms with the conference-goers. The Language and Literacy Researchers of Canada (LLRC) pre-conference offers an intimate environment for working through papers and collaborating on ideas. It is unlike many other conferences because a number of authors (4-5) are put into groups with similar papers, and these papers are circulated before the conference begins. In this way, much of the audience is familiar with the paper, and can provide really thoughtful and in-depth feedback. Rather than a cold and scary environment, this provides authors the opportunity to think through issues in the papers that may have not been previously considered. This presentation setting was unfamiliar to Ann and Katrina, who had never experienced a conference of this kind before. Ann reflected,

I would have expected the conference to be more formal, at least comparatively to the ones that I have attended in the past. I was just so used to being the "small potato" and being surrounded by older and more professional/experienced people in the field during the conference that I wasn't expecting that our presence would be such a big deal or make such a huge impact on others. In fact, all I did was share my experiences as an ethnic minority living in Hong Kong (which is ultimately the results of the research) and it was probably the first time that more experienced people (or should I say "adults") were so keen so listen to what I have to say.

This time, I didn't have to say anything technical, just stood there, speaking [about] what I experienced and what my life is like and others... appreciated and understood 
these struggles. I felt more belong[ing] than I did whenever I speak about my issues in Hong Kong. It felt wonderful to find others, on the other side of the world, who could understand and value what you have to say and what you went through.

Even if 8 hours of [a] conference is nothing compared to the longer hours I spent in my past experiences...I learned a lot and realized that I'm not alone in my struggles. That essentially, ethnic minorities aren't alone. I got to know things that I wasn't aware of before, like the realities of Indigenous peoples [in Alexis Brown $\&$ Deborah Begoray's study, see this issue] and Mennonites [in Christine Kampen Robinson's study, see this issue]. That's the thing about conferences and travelling: it opens your worldview and expands your knowledge out of the box.

The audience reaction to our co-presentation was extremely warm, engaged, and provided thoughtful critiques. One audience member asked if we would consider going back and asking ethnic minority young people in Hong Kong about how they might imagine a better reality for others in the city. This line of questioning has inspired us to continue our collaboration, but this time, with Katrina and Ann as the main researchers, and Casey providing support. In the next year, we plan to work with school-aged ethnic minority young women in Hong Kong to create short cellphilms that articulate their community strengths and imagine an inclusive future for themselves in Hong Kong. We want the girls to create visual responses to the following questions: What might an inclusive Hong Kong look like? What would it take to get there?

The audience reflections from the LLRC pre-conference have inspired us to continue our project working with youth in an effort to imagine and then act on change within Hong Kong. In terms of project sustainability, the practice of co-presenting, and sharing our research with new audiences has led to the development of a girl-led from-theground-up cellphilm project where Katrina and Ann will take on the roles of researchers, organizers, and support other girls to become co-researchers.

The environment at the LLRC conference encouraged Ann and Katrina to speak confidently about their experiences as research participants, but also as co-researchers, and knowledge holders. They were experts, and disseminated the research findings to an academic audience with my support. In so doing, the participatory nature of the research was able to be continued from the initial inquiry to the sharing of the knowledge across a number of spaces and to different audiences: Hong Kong community members in our work in the city, global audiences through our YouTube-based participant managed digital archive, and North American academic audiences through our paper collaboration and the presentation of our findings at the LLRC pre-conference. I argue that this in-person collaboration is another multiliteracy practice within the research for social change framework, as again, we worked to share the research findings with new audiences, learn more about what these audiences value in the research and where they suggest that the project might develop in the future. Most importantly, the conversations with the audience that came out of the conference has led us to continue to collaborate on a new project, tentatively called \#OwnVoices. 


\section{Concluding Thoughts: It's Our HK Too}

This study describes a participatory visual collaboration with two Filipina coresearchers through cellphilming, collaborative writing for an academic journal, and copresenting our findings at the 2016 LLRC pre-conference as multiliteracy practices in a research for social change framework. Ann and Katrina-as Filipina young womendescribe their sense of civic engagement through disruptive productions of citizenship, including participating in the Occupy Movement, and describing their dissenting actions and feelings. They also take up traditional notions of citizenship, including the desire to participate in voting, but argue that they must take real action (including activism) in order to participate. The creation of a digital archive on YouTube provides an opportunity for cellphilms to be meaningfully disseminated to a number of communities, and gives the girls an opportunity to reach new audiences. In an effort to engage multiple audiences and work toward impacting academics and policy makers, collaborating on a peer-reviewed academic article and co-presenting at an academic conference provide opportunities for these Filipina young women to describe their sense of self and civic engagement while reaching populations that may not reach through the dissemination of their visual productions shared on YouTube. In a research for social change framework, this study finds that participatory visual research projects with participants as co-inquirers must contend with the notions of audience motivation to work with participants to impact the audiences that might best be equipped to make social change. Sharing cellphilms through community screenings (Burkholder, forthcoming) as well as through a digital archive might best impact community members to demand social action. Collaborating on academic writing and presenting might best impact policy makers and academics who might have the opportunity to also make real change for ethnic minorities in Hong Kong. The study also argues that the Occupy Movement acted as a catalyst for Filipina youth activism, where the physical occupation of key spaces in Hong Kong encouraged young people to think critically about their sense of belonging and what it means to act as a citizen in Hong Kong. If, as Katrina suggests, “before Occupy Central, I wasn't concerned," I wonder: Would these young women have been so interested in sharing their sense of civic engagement? Would they have wanted to continue to collaborate, to share their protest experiences, and to work to impact different audiences in an effort to work toward social change? What is certain is that the Occupy Movement encouraged the young women to view themselves as active participants in Hong Kong's political present and future, and inspired them to continue to collaborate in a participatory visual research project in an effort to make Hong Kong a more inclusive and democratic place for its ethnic minority citizens.

\section{References}

Arnot, M., \& Dillabough, J. A. (2000). Challenging democracy: International perspectives on gender, education and citizenship. London: Psychology Press.

Barton, D. \& Hamilton, M. (1998). Understanding literacy as a social practice. In D. Barton \& M. Hamilton (Eds.) Local literacies: Reading and writing in one community, (pp. 3-22). London and New York: Routledge.

Barton, D. \& Hamilton, M. (2001). Literacy practices. In D. Barton, M. Hamilton \& R. Ivanic (Eds.). Situated literacies: Reading and writing in context, (pp. 7-15). London and New York: Routledge. 
Blackburn, M. V., \& Clark, C. T. (Eds.) (2007). Literacy research for political action and social change (Vol. 310). New York: Peter Lang.

Buckingham, D. (2000). The making of citizens: Young people, news and politics. London, UK and New York: Routledge.

Buckingham, D. \& Sefton-Green, J. (1994). Cultural studies goes to school. London: Taylor \& Francis.

Burkholder, C. (2013). 'Just the school makes us non-Chinese': Contrasting the discourses of Hong Kong's Education Bureau with the lived experiences of its Non-Chinese Speaking secondary school population. Journal of Educational Research for Social Change, 2(2), 43-58.

Burkholder, C. (2016a). On keeping public visual fieldnotes as reflexive ethnographic practice. McGill Journal of Education, 51(2), 907-916.

Burkholder, C. (2016b). We are HK too!: Disseminating cellphilms in a participatory archive. In K. MacEntee, C. Burkholder, and J. Schwab-Cartas (Eds.). What's a cellphilm?: Integrating mobile phone technology into participatory visual research and activism. Rotterdam: Sense Publishers.

Burkholder, C. (2017). Who's Hong Kong? Cellphilming and civic engagement with ethnic minority youth. In S. Malik, C. Chapain \& R. Comunian (Eds.). Community filmmaking: Diversity, innovation, policy and practice. New York, NY and London, UK: Routledge.

Cope, B., \& Kalantzis, M. (2000). Multiliteracies: Literacy learning and the design of social futures. London and New York: Routledge.

Choudry, A. \& Kapoor, D. (2010). Learning from the ground up: Global perspectives on social movements and knowledge production. New York: Palgrave MacMillan.

Couldry, N. (2010). Why voice matters: Culture and politics after neoliberalism. Thousand Oaks: Sage Publications.

Dockney, J. \& Tomaselli, K. G. (2009). Fit for the small(er) screen: Films, mobile TV and the new individual television experience. Journal of African Cinema, 1(1), $126-132$.

Dyer, C. \& Choksi, A. (2001). Literacy, schooling and development. In B. Street (Ed.), Literacy and development: Ethnographic perspectives (pp. 27-39). London and New York: Routledge.

Ewald, W., Hyde, K. \& Lord, L. (2012). Literacy and justice through photography: A classroom guide. New York: Teacher College Press.

Gee, J.P. (1996). Social linguistics and literacies: Ideology in discourses. London: RoutledgeFalmer.

Gee, J.P. (2001). Literacy, discourse and linguistics: Introduction and what is literacy? In E. Cushman, E. Kingten, B.M. Kroll \& M. Rose (Eds.), Literacy: A critical sourcebook, (pp. 525-544). Boston: Belford/St. Martin's.

Goodman, S. (2003). Teaching youth media: A critical guide to literacy, video production \& social change (Vol. 36). New York: Teachers College Press.

Gubrium, A. \& Harper, K. (2013). Participatory visual and digital methods. Walnut Creek: Left Coast Press.

Harris, A. (2005). Future girl: Young women in the twenty-first century. New York: Routledge. 
HKSAR (Hong Kong Special Administrative Region). (2011). Hong Kong 2011 population census thematic report: Ethnic minorities. [Report]. Retrieved from: http://www.censtatd.gov.hk/hkstat/sub/sp170.jsp?productCode=B1120062

Jenkins, H. (2016). Youth voice, media and political engagement. In H. Jenkins, S. Shresthova, L. Gamber-Thompson, N. Kligler-Vilenchik, \& A. Zimmerman (Eds.), By any media necessary: The new youth activism, (pp. 1-60). New York: NYU Press.

Jones, R. H., \& Li, N.C.H. (2016). Evidentiary video and "professional vision" in the Hong Kong umbrella movement. Journal of Language and Politics, 15(5), 569591.

Ku, A. S., \& Pun, N. (Eds.). (2011). Remaking citizenship in Hong Kong: Community, nation and the global city (Vol. 6). New York: Routledge.

MacEntee, K., Burkholder, C., \& Schwab-Cartas, J. (Eds.). (2016). What's a cellphilm?: Integrating mobile phone technology into participatory visual research and activism. Rotterdam: Sense Publishers.

Marshall, T. H. (1977). Class, citizenship and social development: Essays by TH Marshall. Chicago: University of Chicago Press.

Milne, E.-J., Mitchell, C., \& De Lange, N. (2012). Handbook of participatory video. Plymouth: AltaMira.

Mitchell, C. (2011). Doing visual research. Los Angeles: Sage.

Mitchell, C. \& Burkholder, C. (2015). Chapter 43: Literacies and research as social change. In J. Rowsell and K. Pahl (Eds.). Routledge Handbook of Literacy Studies, (pp. 649-662). London and New York: Routledge.

Mitchell, C., De Lange, N., \& Moletsane, R. (2016). Poetry in a pocket: The cellphilms of South African rural women teachers and the poetics of the everyday. In K. MacEntee, C. Burkholder, \& J. Schwab-Cartas (Eds.), What's a cellphilm? Integrating mobile technology into visual research and activism (pp. 19-34). Rotterdam: Sense.

Mitchell, C., De Lange, N., \& Moletsane, R. (2011). Before the cameras roll: Drawing storyboards to address gendered poverty. In L. Theron, C. Mitchell, A. Smith, \& J. Stuart (Eds.), Picturing research: Drawing as visual methodology (pp. 119231). Rotterdam: Sense.

Mitchell, C., \& De Lange, N. (2013). What can a teacher do with a cellphone? Using participatory visual research to speak back in addressing HIV\&AIDS. South African Journal of Education, 33(4), 1-13.

Mitchell, C., De Lange, N., \& Moletsane, R. (2016). Poetry in a pocket: The cellphilms of South African rural women teachers and the poetics of the everyday. In K. MacEntee, C. Burkholder, \& J. Schwab-Cartas (Eds.), What's a cellphilm? Integrating mobile (pp. 19-34). Rotterdam: Sense

Mitchell, C., De Lange, N., \& Moletsane, R. (2014). Me and my cellphone: Constructing change from the inside through cellphilms and participatory video in a rural community. Area, 1-7. doi:10.1111/area.12142

Mitchell, C., Stuart, J., De Lange, N., Moletsane, R., Buthelezi, T., Larkin, J. \& Flicker, S. (2010). What difference does this make? Studying Southern African youth as knowledge producers with a new literacy of HIV and AIDS. In C. Higgins and B. 
Norton (Eds.), Language and HIV/AIDS, (pp. 214-232). Clevedon: Multilingual Matters.

The New London Group. (1996). A pedagogy of multiliteracies: Designing social futures. Harvard educational review, 66(1), 60-93.

Packham, C. (2008). Active citizenship and community learning. Los Angeles: Learning Matters.

Rogers, T., Winters, K.-L., Perry, M. \& A.-M. LaMonde. (2015). Youth, critical literacies, and civic engagement: Arts, media, and literacy in the lives of adolescents. New York: Routledge.

Roholt, R. V., Baizerman, M., \& Hildreth, R. W. (2014). Becoming citizens: Deepening the craft of youth civic engagement. New York: Routledge.

Rose, G. (2014). On the relation between 'visual research methods' and contemporary visual culture. The Sociological Review, 62(1), 24-46. doi:10.1111/1467954X.12109

Rowsell, J. \& Pahl, K. (Eds.). Routledge handbook of literacy studies. London and New York: Routledge.

Schratz, M. \& Walker, R. (1995). Research as social change: New possibilities for qualitative research. London and New York: Routledge.

Schwab-Cartas, J. (2012). Learning from communities: Personal reflections from inside. In E.J. Milne, C. Mitchell and N. De Lange (Eds.), Handbook of Participatory Video, (pp. 383-396). Lanham: AltaMira Press.

Singhal, A., \& Rogers, E. (2012). Entertainment-education: A communication strategy for social change. London and New York: Routledge.

Street, B. V. (2014). Social literacies: Critical approaches to literacy in development, ethnography and education. London and New York: Routledge.

Stuart, J. \& Mitchell, C. (2013). Media, participation, and social change: Working within a 'youth as knowledge producers' framework. In D. Lemish (Ed.), The Routledge international handbook of children, adolescents and media, (pp. 359-365). New York: Routledge.

Theron, L., Mitchell, C., Smith, A., and Stuart, J. (Eds.). (2011). Picturing research: Drawing $(s)$ as visual methodology. Rotterdam: Sense Publishers.

Turner, B. S. (1990). Outline of a theory of citizenship. Sociology, 24(2), 189-217.

Wang, C. (1999). Photovoice: Participatory action research strategy applied to women's health. Journal of Women's Health, 8(2), 185-192.

Wang, C. \& Burris, M. (1997). Photovoice: Concept, methodology and use for participatory needs assessment. Health Education and Behavior, 24(3), 369-387.

Walsh, S. (2014). Critiquing the politics of participatory video and the dangerous romance of liberalism. Area, n/a-n/a. doi:10.1111/area.12104 


\section{Author Biography}

Casey Burkholder is a PhD Candidate at McGill University, a teacher-educator, and participatory visual researcher. She first became invested in the relationships between space, belonging, and civic engagement from a young age, growing up in Canada's North. In choosing a research path at the intersection of citizenship, gender, inclusion, DIY media-making, and Social Studies education, Casey believes her work may contribute to 'research as intervention' (Mitchell, 2011) through participatory approaches to equity and social change. 